\title{
CALCIPHYLAXIS INVOLVING BOTH THE UPPER AND LOWER EXTREMITIES
}

\author{
Tulay Ozer ${ }^{1}$, Ali Borazan ${ }^{2}$, Mubin Hosnuter ${ }^{3}$, Eksal Kargi ${ }^{3}$, Ahmet Savranlar ${ }^{1}$, Ahmet Yilmaz $^{4}$ \\ Karaelmas University School of Medicine, Turkey: Department of Radiology ${ }^{1}$, Department of Internal Medicine ${ }^{2}$, \\ Department of Plastic and Reconstructive Surgery33 Kocaeli University School of Medicine, Turkey: Department of \\ Nephrology ${ }^{4}$
}

Summary: Calciphylaxis is an uncommon complication of end stage renal disease (ESRD) and secondary hyperparathyroidism. It characterized by cutaneous necrosis with mural calcifications and thrombosis in the small vessels of dermis. It is important to diagnose and treat, because of mortality rate from calciphylaxis is very high. We present the case of a patient with ESRD and type II diabetes mellitus developing calciphylaxis of the both upper and lower extremities had normal corrected calcium-phosphate product level. After amputation, necrosis was showed rapid progression resulting in death in one month.

Key words: Calciphylaxis

\section{Introduction}

Calciphylaxis is a rare, life threatening and debilitating condition found in patients with end stage renal disease (ESRD). Usually there is an elevated phosphate level and secondary hyperparathyroidism, ensuing increased calcium-phosphate product. This causes deposition of calcium phosphate in tissues and in both small and intermediate dermal vessels. Less commonly, cutaneous calcification in this disease can occur with normal serum calcium and phosphate levels (12). Although exact pathogenesis is not known, certain trigger factors, such as trauma, albumin, sepsis, iron supplementation, and corticosteroid therapy can precipitate the calcium deposition in vulnerable patients (17). Patients are usually admitted or referred to surgical clinics suffering from painful, red to purple livedoid plaques that may involve the full thickness of the skin, and subcutaneous tissue. In a few days, these areas become necrotic, eventually leading to extensive ulcerations. The lesions most commonly occur at lower extremities. This article reports of a rare case, who presented with calciphylactic skin necrosis on both upper and lower extremity with normal serum corrected calcium-phosphate product level.

\section{Case report}

A 48 year-old man with a 4-year history of peritoneal dialysis caused by diabetic nephropathy was referred to our clinic because of full thickness painful skin necrosis on the feet and hands. He had been diagnosed with type II diabetes mellitus 12 year earlier but discontinued regular treatment. Beside, he had a long-standing history of hypertension and ischemic hearth disease. His medications included erythropoietin, iron preparations, doksazosin, amlodipin, and valsartan. Patient stated that the lesions had begun as a purple discoloration resembling purpura. Eventually, these lesions extended peripherally and progressed to full-thickness skin necrosis and scar, indicating deep necrosis of the subcutaneous fat to the level of the investing muscular fascia. The patient especially complained intense pain and itching at the wound sites. Physical examination revealed the pale conjunctivas and the skin, cyanotic-painful fingers on extremities, and the cutaneous necrosis areas on the feed and hands (Fig. 1). Laboratory findings were as follows: Na, 133 $\mathrm{mmol} / \mathrm{L}$ (137-145 mmol/L); K, 3,2 mmol/L; albumin, 17 $\mathrm{gm} / \mathrm{L}(35-50 \mathrm{gm} / \mathrm{L})$; sedimentation rate $70 \mathrm{~mm} / \mathrm{h}$; calcium (Ca), $2.45 \mathrm{mmol} / \mathrm{L}(2.1-2.6 \mathrm{mmol} / \mathrm{L})$; corrected $\mathrm{Ca}$ for hypoalbuminemia, $2.9 \mathrm{mmol} / \mathrm{L}$; ionized $\mathrm{Ca}, 1.3 \mathrm{mmol} / \mathrm{L}$ (0.8-1.2 mmol/L); phosphate, $1.49 \mathrm{mmol} / \mathrm{L}(0.8-1.45$ $\mathrm{mmol} / \mathrm{L})$; corrected calcium- phosphate, $53.36 \mathrm{mg}^{2} / \mathrm{dL}^{2}$. He was found to have a significant degree of hyperparathyroidism, with parathyroid hormone (PTH) level: 658 $\mathrm{ng} / \mathrm{L}$ (15-65 ng/L). Markedly elevated serum urea: 45.3 $\mathrm{mmol} / \mathrm{L}(3.5-17 \mathrm{mmol} / \mathrm{L})$ and creatinine: $804.4 \mu \mathrm{mol} / \mathrm{L}$ $(70-106 \mu \mathrm{mol} / \mathrm{L})$ levels were identified due to chronic state of uremia.

Bilateral plain roentgenograms of the extremities revealed extensive calcification in the arteries and the sub- 

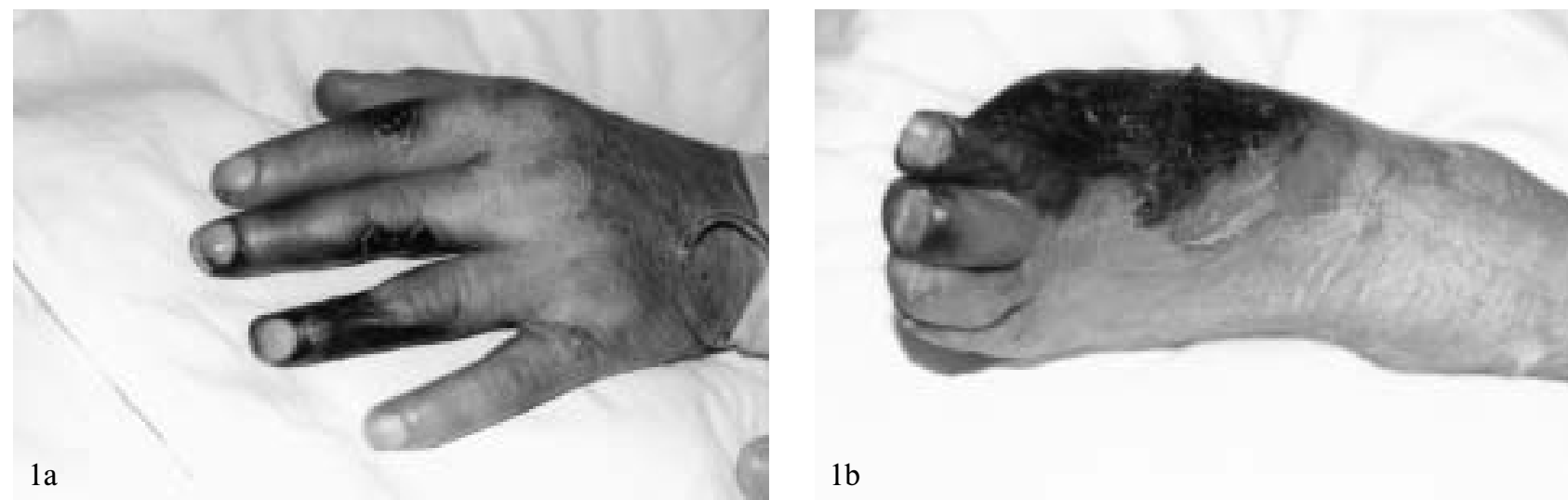

Fig. 1: The appearance of the extremities of this patient. Established necrotic areas on the fingers are seen (a). The toe of the left foot had been amputated (b).

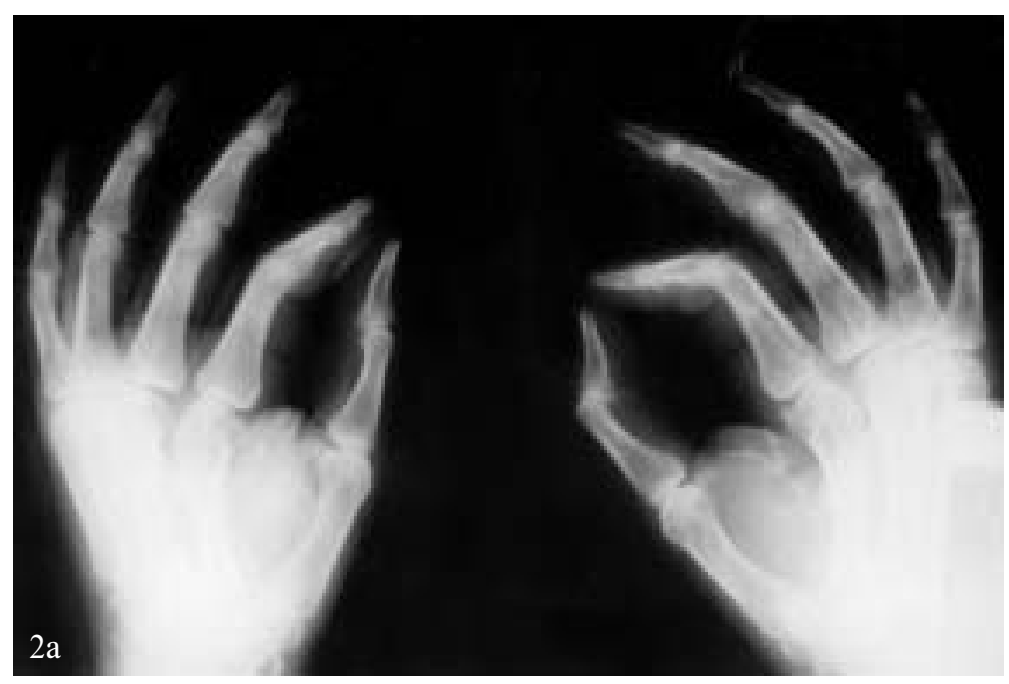

Fig. 2: Plain radiographs of both upper and lower extremities of the patient with calciphylaxis. Extensive calcifications can be seen in digital arteries of both hand (a) and small and large vessels of the thigh (b).

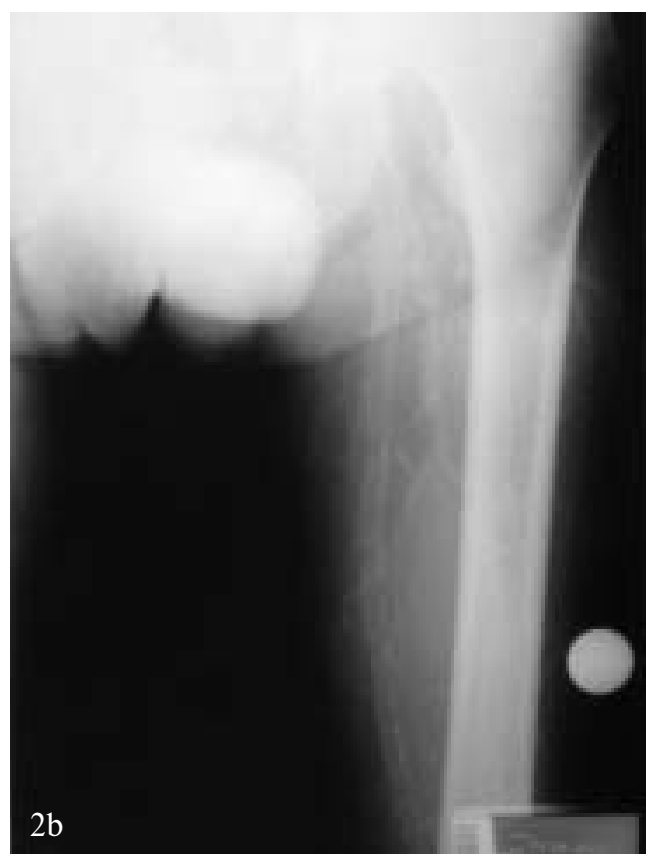

cutaneous tissue (Fig. 2). Arterial Doppler ultrasonography of lower extremities showed non-pulsating peripheral vessels because of massive calcified plaques in wall of the vessels. Angiography showed occlusion at the level of two thirds distal of the anterior tibialis vessel. On echocardiography, degenerative changes of the aorta and mitral valves, left ventricular hypertrophy, and left atrium enlargement were found. Microscopic examination of biopsy specimens taken from lesions demonstrated fat necrosis with extensive calcifications of small vessel's media and intimal hyperplasia. All findings were consistent with calciphylaxis with no evidence of vasculitis. This case was diagnosed as calciphylaxis according to his biochemical, clinical and histopathological features. The patient received hemodialysis for the treatment of uremia during hospitalization and ray- amputation was done for his left foot's first finger. Unfortunately, the necrosis showed rapid progression after amputation and the patient expired within a month as a result of sepsis and multiple organ failure.

\section{Discussion}

The most severe complication of the abnormal calcium and phosphate metabolism of ESRD is calciphylaxis. This disorder was first reported by Bryant in 1899 (3) and then subsequent studies named it as either calciphylaxis or uremic gangrene syndrome $(17,19)$. Affected patients are characteristically dialysis dependent and suffer from secondary or tertiary hyperparathyroidism with high level of serum calcium-phosphate product $\left(>70 \mathrm{mg}^{2} / \mathrm{dL}^{2}\right)$ [12]. In 
the case reported here, the level of the serum corrected calcium-phosphate were normal. The pathogenesis remains unexplained, but the term calciphylaxis is often used because of the similarity of findings with those occurring in rats in experiments by Selye who induced hypercalcaemia in the human. Uremia and hyperphosphataemia are often more obvious than hypercalcaemia. The high calciumphosphate product level $\left(>70 \mathrm{mg}^{2} / \mathrm{dL}^{2}\right)$ is the most important determinant, but some patients with normal calcium and phosphate level do develop calciphylaxis $(17,19)$.

The media of blood vessels in the involved tissue is usually calcified. The affected vessels may show intravascular thrombosis, without inflammation. Firstly, calciphylaxis appears as reticulated, violaceous, mottled patches, soon after progressing to ecchymosis, cordlike nodules, livedo reticularis, or necrosis $(5,8,12)$. Gangrene and self amputation of digits or extremities has been reported $(4,18)$. The lesions most commonly occur below the knees, and if restricted to below midcalf and to the fingers (distal type), the prognosis is good, with a $70 \%$ survival rate. Extensive lesions in proximal type usually affect the buttocks, thighs, shoulders and trunk are very bad prognosis, with a mortality rate of more than $85 \%$ in some series (14). Necrosis may involve other sites, such as the penis, tongue, breast, muscle or bowel $(2,6,11,15)$.

The pathogenic mechanism is related to predisposing conditions that create a conducive environment for calcium precipitation in sensitized patients. Calcification occurs when an appropriate challenging factor is then introduced. Identified sensitizers include vitamin D compounds, parathyroid hormone, phosphates, and calcium salts, as well as infections, particularly granulomatous disorders, and cryofibrinogenemia. Challenging agents include metallic salts, local trauma, certain organic compounds (albumin and egg yolk), corticosteroids, intramuscular iron dextran complex, calcium heparinate, and intramuscular tobramycin. The sensitizing event and the challenging insult don't have to occur at the same time to cause disease $(10,17)$. Patients with diabetes and chronic renal failure have a much higher risk of developing acral gangrene (16). The reported case is a good example of this condition. Poorly compensated diabetes, underdialysis, high ionized calcium (with high total calcium when corrected to low albumin level) may be the other factors that precipitating the calciphylaxis in our patient. The differential diagnosis includes pyoderma gangrenosum, necrotizing vasculitis, purpura fulminans, autoimmune vasculitis, peripheral vascular diseases, cryoglobulinemia, diabetes, warfarin-induced skin necrosis, disseminated intravascular coagulation, and bacterial endocarditis $(5,12,18)$.

Treatment of calciphylaxis is difficult. Prevention is the best option, if possible, by management of the elevated phosphate levels with binding agents. Once lesions begin to appear, parathyroidectomy may be considered. Patients with parathyroid disease have the best prognosis after parathyroidectomy with autotransplantation of parathyroid tissue (9). The parathyroid glands are removed totally but small piece of gland is buried in to muscle. If the disease process continues, the transplanted gland is also removed. Uremia and hypercalcemia should be corrected. Hyperbaric oxygen therapy and administration of prednisone, cimetidine, and systemic corticosteroids have been suggested as medical management $(1,7,10)$. Intensive wound care, administration of antibiotics, debridement of necrotic tissue, corrections of electrolytes are most important factors in preventing sepsis $(10,12,18)$. Death is usually caused by uncontrollable sepsis after infection of the chronic ulcerations.

\section{References}

1. Basile $\mathrm{C}$, Montanaro A, Masi $\mathrm{M}$ et al. Hyperbaric oxygen therapy for calcific uremic arteriolopathy: a case series. J Nephrol 2002;15:676-80.

2. Bedoya RM, Gutierrez JL, Mayorga F. Calciphylaxis causing localized tongue necrosis: a case report. J Oral Maxillofac Surg 1997;55:193-6.

3. Bryant $\mathrm{JH}$, White WH. A case of calcification of the arteries and obliterative endarteritis associated with hydronephrosis in a child aged six months. Guys Hosp Rep 1899;55:17-9.

4. Duh QY, Lim RC, Clark OH. Calciphylaxis in secondary hyperparathyroidism diagnosis and parathyroidectomy. Arch Surg 1991;126:1213-9.

5. Edwards RB, Jaffe W, Arrowsmith $\mathrm{J}$ et al. Calciphylaxis: a rare limb and life threatening cause of ischemic skin necrosis and ulceration. Br J Plast Surg 2000;53:253-5

6. Flanigan KM, Bromberg MB, Gregory $\mathrm{M}$ et al. Calciphylaxis mimicking dermatomyositis: ischemic myopathy complicating renal failure. Neurology 1998;51:1634-40

7. Gilson RT, Milum E. Calciphylaxis: case report and treatment review. Cutis 1999; 63:149-53

8. Gipstein RM, Coburn JM, Adams DA et al. Calciphylaxis in man: a syndrom of tissue necrosis and vascular calcification in 11 patients with chronic renal failure. Arch Intern Med 1976;136:1273-80.

9. Girotto JA, Harmon JW, Ratner LE et al. Parathyroidectomy promotes wound healing and prolongs survival in patients with calciphylaxis from secondary hyperparathyroidism. Surgery 2001:130:645-50

10. Howe SC, Murray JD, Reeves RT et al. Calciphylaxis, a poorly understood clinical syndrome: three case reports and a review of the literature. Ann Vasc Surg 2001;15:470-3.

11. Jacobsohn HA, Jenkins PG, Jacobsohn KM. Penile calciphylaxis. Urology 2002; 60:344-7.

12. Kane WJ, Petty PM, Sterioff S et al. The uremic gangrene syndrome: improved healing in spontaneously forming wounds following subtotal parathyroidectomy. Plast Reconstr Surg 1996;98:671-8.

13. Mehta RL, Scott G, Sloard JA et al. Skin necrosis associated with acquired protein $\mathrm{C}$ deficiency in patients with renal failure and calciphylaxis. Am J Med 1990;88:252-7.

14. Odom RB, James WD, Berger TG. Andrew's Diseases of The Skin; in Errors in Metabolism. Philadelphia: W.B. Saunders Comp, 2000:660.

15. Patetsios P, Bernstein M, Kim S et al. Severe necrotizing mastopathy caused by calciphylaxis alleviated by total parathyroidectomy. Am Surg 2000;66:1056-8.

16. Scheinman PL, Helm KF, Fairley JA. Acral necrosis in a patient with chronic renal failure. Calciphylaxis. Arch Dermatol 1991;127:248-9.

17. Selye H, Gabbiani G, Strebel R. Sensitization of calciphylaxis by endogenous parathyroid hormone. Endocrinology. 1962;71:554-8.

18. Senturk S, Hosnuter M, Tosun $\mathrm{Z}$ et al. Calciphylaxis: Cutaneous necrosis in chronic renal failure. Ann Plast Surg 2002;48:104-5.

19. Torok L, Kozepessy L. Uraemic gangrene syndrome. Acta Dermatol Venereol 1991;71:455-7.

Submitted June 2004.

Accepted September 2004.

Tulay Ozer, MD,

Zonguldak Karaelmas Üniversitesi Tip

Fakültesi Hastanesi Radyoloji A.D.

67600, Kozlu, Zonguldak-Turkey.

e-mail: tulayozer@tnn.net 